\title{
Echocardiographic detection of transpulmonary bubble transit during acute respiratory distress syndrome
}

\author{
Florence Boissier ${ }^{1,2,3}$, Keyvan Razazi ${ }^{1}$, Arnaud W Thille ${ }^{1,4}$, Ferran Roche-Campo 1,5, Rusel Leon ${ }^{1,6}$, Emmanuel Vivier ${ }^{1,7}$, \\ Laurent Brochard ${ }^{8}$, Christian Brun-Buisson ${ }^{1,2,3}$ and Armand Mekontso Dessap ${ }^{1,2,3^{*}}$
}

\begin{abstract}
Background: Transpulmonary bubble transit (TPBT) detected with contrast echocardiography is reported as a sign of intrapulmonary shunt during cirrhosis or exercise in healthy humans. However, its physiological meaning is not clear during acute respiratory distress syndrome (ARDS). Our aim was to determine the prevalence, significance, and prognosis of TPBT detection during ARDS.

Methods: This was a prospective observational study in an academic medical intensive care unit in France. Two hundred and sixteen consecutive patients with moderate-to-severe ARDS underwent transesophageal echocardiography with modified gelatine contrast. Moderate-to-large TPBT was defined as right-to-left passage of at least ten bubbles through a pulmonary vein more than three cardiac cycles after complete opacification of the right atrium. Patients with intra-cardiac shunt through patent foramen ovale were excluded.

Results: The prevalence of moderate-to-large TPBT was 26\% (including 42 patients with moderate and 15 with large TPBT). Patients with moderate-to-large TPBT had higher values of cardiac index and heart rate as compared to those without TPBT. There was no significant difference in $\mathrm{PaO}_{2} / \mathrm{FIO}_{2}$ ratio between groups, and TPBT was not influenced by end-expiratory positive pressure level in $93 \%$ of tested patients. Prevalence of septic shock was higher in the group with moderate-to-large TPBT. Patients with moderate-to-large TPBT had fewer ventilator-free days and intensive care unit-free days within the first 28 days, and higher in-hospital mortality as compared to others.
\end{abstract}

Conclusions: Moderate-to-large TPBT was detected with contrast echocardiography in $26 \%$ of patients with ARDS. This finding was associated with a hyperdynamic and septic state, but did not influence oxygenation.

Keywords: Echocardiography; Acute respiratory distress syndrome; Shunt

\section{Background}

Determinants of hypoxemia during acute respiratory distress syndrome (ARDS) are multiple. They may include effect of low mixed venous oxygen tension $\left(\mathrm{PvO}_{2}\right)$ on arterial oxygen tension [1], intra-cardiac right-to-left shunt [2], low ventilation-perfusion ratio [3], or intrapulmonary shunt [3]. Intrapulmonary shunt during ARDS may result from perfused but non-aerated lung areas secondary to dilated pulmonary vessels or to alveolar edema

\footnotetext{
* Correspondence: armand.dessap@hmn.aphp.fr

${ }^{1}$ AP-HP, Hôpital Henri Mondor, DHU A-TVB, Service de Réanimation Médicale, Groupe de recherche CARMAS, 51 Av Mal de Lattre de Tassigny, Créteil 94010, France

${ }^{2}$ INSERM, Unité U955 (IMRB), 8 rue du Général Sarrail, Créteil 94010, France Full list of author information is available at the end of the article
}

and collapse. Areas of alveolar edema and collapse predominate in the basal and dependant regions of the lung. Mechanical ventilation and positive end-expiratory pressure (PEEP) may alter the distribution of ventilation and perfusion and the magnitude of intrapulmonary shunt [4,5]. Measurement of intrapulmonary shunt could help assessing ARDS severity and the effect of some therapeutic interventions on perfused but non-aerated lung areas. Intrapulmonary shunt measurement is difficult, and two main methods have been evaluated: estimation of 'functional' shunt (using Riley's venous admixture Qs/Qt) [6] and estimation of 'anatomical' shunt (using multiple inert gas technique [7] or lung computed tomography scan $[8])$. 
Contrast echocardiography is able to detect transpulmonary bubble transit (TPBT) at bedside. This method is routinely used to detect physiological intrapulmonary shunt in healthy humans at rest [9] or during exercise [10] and hepato-pulmonary syndrome in cirrhosis [11]. However, TPBT may not be strictly ascribable to intrapulmonary shunt in the context of ARDS. The objectives of our study were to determine the prevalence, physiological significance, and prognosis of TPBT detected with contrast echocardiography during ARDS. This study includes some patients previously described in reports focusing on patent foramen ovale and acute cor pulmonale during ARDS $[2,12]$.

\section{Methods}

\section{Patients}

Patients who met the Berlin definition criteria for moderateto-severe ARDS (respiratory failure within 1 week of a known clinical insult or new or worsening respiratory symptoms; with bilateral chest opacities not fully explained by effusions or lobar/lung collapse or nodule, and not fully explained by cardiac failure or fluid overload; and a $\mathrm{PaO}_{2} / \mathrm{FiO}_{2}$ ratio $\leq 200 \mathrm{mmHg}$ with $\mathrm{PEEP} \geq 5 \mathrm{cmH}_{2} \mathrm{O}$ ) [13] and who underwent transesophageal echocardiography (TEE) within the first three days after the diagnosis were included prospectively between June 2004 and August 2011 at the medical intensive care unit (ICU) of Henri Mondor Hospital (Creteil, France). Non-inclusion criteria were contraindications to TEE (esophageal disease or major uncontrolled bleeding), and chronic pulmonary disease requiring long-term oxygen therapy or home mechanical ventilation. The study was approved by the institutional ethics committee of the French Society of Intensive Care (Société de Réanimation de Langue Française). Because we routinely use TEE to assess the circulatory status of mechanically ventilated patients with ARDS in our ICU, TEE was considered a component of standard care and patient's consent was waived. Written and oral information about the study was given to the families. Follow-up for the study was until hospital discharge.

\section{Respiratory settings}

Ventilation was in volume-assist control mode, with a target tidal volume $\left(V_{\mathrm{T}}\right)$ of $6 \mathrm{~mL} / \mathrm{kg}$ of predicted body weight. In patients with persistent severe hypoxemia $\left(\mathrm{PaO}_{2} / \mathrm{FiO}_{2}<\right.$ $100 \mathrm{mmHg}$ ) despite a PEEP level as high as possible without exceeding a maximal inspiratory plateau pressure (Pplat) of 28 to $30 \mathrm{cmH}_{2} \mathrm{O}$ [14], prone positioning and/or inhaled nitric oxide were used at the discretion of the attending physician. If Pplat exceeded the maximal threshold, $V_{\mathrm{T}}$ could be lowered until Pplat was less than 30 $\mathrm{cmH}_{2} \mathrm{O}$; to counterbalance the effect of $V_{\mathrm{T}}$ reduction on alveolar ventilation, the respiratory rate was increased to the highest rate that did not induce intrinsic PEEP [15]. Driving pressure was defined as the difference between Pplat and PEEP. Oxygenation index was computed as $\mathrm{FiO}_{2}{ }^{*}[(2$ plateau pressure $+\mathrm{PEEP}) / 3] / \mathrm{PaO}_{2}[16]$.

\section{Echocardiography}

TEE was performed using a Sonos 5500, Envisor, or a IE 33 system (Philips Ultrasound, Bothell, WA, USA) equipped with a multiplane $5-\mathrm{MHz}$ transesophageal echocardiographic transducer, by trained operators (competence in advanced critical care echocardiography) [17], using a standard procedure [18]. Briefly, the following echocardiographic views were examined: long-axis M-mode view of the superior vena cava (SVC) to assess its collapsibility; four-chamber long-axis view to assess the end-diastolic right ventricle/left ventricle $(\mathrm{RV} / \mathrm{LV})$ area ratio and $\mathrm{LV}$ ejection fraction; short-axis view of the LV via the transgastric approach to evaluate the kinetics of the interventricular septum. Pulsed-wave Doppler aortic flow was obtained at the level of the aortic annulus, and the velocitytime integral was automatically processed by tracing the envelope of aortic flow for cardiac index calculation. Cor pulmonale was defined as a dilated right ventricle (end-diastolic RV/LV area ratio >0.6) associated with paradoxical septal motion on the short-axis view [19]. Echocardiographic images were recorded, and a computerassisted evaluation was performed off-line by two trained senior sonographers (FB, AMD). When possible, transthoracic echocardiography was also performed to assess pulmonary artery systolic pressure (PASP), using the tricuspid regurgitation continuous-wave Doppler technique. Undetectable values of tricuspid regurgitation were assigned a PASP value lower than any actually measured during the study $(20 \mathrm{mmHg})$. A longitudinal view of the fossa ovalis was obtained to evaluate right-toleft shunting by injecting $9.5 \mathrm{~mL}$ of sterile-modified fluid gelatine solution (Plasmion [Fresenius-Kabi, Sevres, France] or Gelofusine 4\% [B-Braun Medical, BoulogneBillancourt, France]) aerated with $0.5 \mathrm{~mL}$ of room air via two syringes connected with a three-way stopcock, as previously described $[2,11]$. The injection was considered successful if the entire right atrium was opacified with microbubble-induced contrast. Up to three successful contrast studies were performed on each patient. Patent foramen ovale (PFO) shunting was defined as right-to-left passage of bubbles through a valve-like structure within three cardiac cycles after complete opacification of the right atrium [2,17]. TPBT was defined as right-to-left passage of bubbles through a pulmonary vein more than three cardiac cycles after complete opacification of the right atrium [11]. TPBT was considered minor, moderate, or large for the passage of one to ten bubbles, ten to 30 bubbles, or more than 30 bubbles, respectively. When the clinical condition and plateau pressure allowed, 
contrast TEE was repeated after decreasing or increasing the PEEP level.

\section{Statistical analysis}

The data were analysed using the SPSS Base 13.0 statistical software package (SPSS Inc., Chicago, IL, USA). Continuous data were expressed as mean \pm standard deviation, unless otherwise specified and were compared using the Mann-Whitney test for two groups comparison. For subgroups analysis, continuous data were compared using the Kruskal-Walis test followed by pairwise Mann-Whitney test with Benjamini-Hochberg correction. Categorical variables, expressed as percentages, were evaluated using the chi-square test or Fisher exact test. Two-tailed $p$ values $<0.05$ were considered significant.

\section{Results}

Patient characteristics

A total of 265 ARDS patients underwent contrast TEE. Forty-nine patients were excluded because of inconclusive contrast study $(n=7)$ or patent foramen ovale $(n=42)$. Thus, the present study includes 216 patients (150 men and 66 women), with a median age of 63 (50 to 76) years. Moderate-to-large TPBT was detected in 57 patients (prevalence of 26\%; 95\% confidence interval 20\% to 32\%). Among the 159 patients without significant TPBT, 120 had no TPBT and 39 had a minor TPBT.

\section{Clinical and echocardiographic findings}

Patients with moderate-to-large TPBT were not significantly different from others regarding clinical characteristics (Table 1). The time elapsed between ARDS onset and TEE was similar in patients with moderate-to-large TPBT as compared to others $(0.9 \pm 0.9$ vs. $0.8 \pm 1.0$ days, $p=0.30$ ). Respiratory settings and arterial blood gases at TEE day were not different between groups except for a lower tidal volume. Prevalence of septic shock was higher in the group with moderate-to-large TPBT (Table 1).

Hemodynamic and echocardiographic variables were similar between groups except for lower values of E/A ratio and higher values of cardiac index, heart rate, and superior vena cava collapsibility in patients with moderateto-large TPBT as compared to others (Table 2). In a subgroup analysis scrutinizing patients with moderate vs. large TPBT, cirrhosis was more prevalent in patients with large TPBT, and $\mathrm{PaCO}_{2}$ values were higher in those with moderate TPBT as compared to others (Table 3 ).

\section{Effect of PEEP level on TPBT}

We studied the effect of PEEP-level changes (7 [5-10] $\mathrm{cmH}_{2} \mathrm{O}$ vs. 15 [15] $\mathrm{cmH}_{2} \mathrm{O}$ ) in 80 patients. TPBT was similar with lower and higher PEEP in the majority $(n=74$, 93\%) of patients (including 57 with absent-or-minor TPBT, and 17 with moderate-to-large TPBT). TPBT was moderate at lower PEEP but minor at higher PEEP in one patient; conversely, TPBT was moderate at lower PEEP but large at higher PEEP in one patient and minor at lower PEEP but moderate at higher PEEP in four patients.

\section{Outcome}

The outcome of patients according to TPBT is displayed in Table 4. The proportion of patients managed during the ICU stay with prone positioning and/or nitric oxide as adjunctive therapy for severe hypoxemia was similar between the groups. The pneumothorax rate during the ICU stay was not different between the groups. There was a trend towards increased ICU mortality rates and a significant increase in hospital mortality rates in patients with moderate-to-large TPBT. Among ICU survivors, mechanical ventilation (MV) duration and ICU duration were longer in patients with moderate-to-large TPBT (Table 4).

\section{Discussion}

The main finding of our study was that moderate-to-large TPBT was detected with contrast echocardiography in $26 \%$ of patients with ARDS. TPBT was associated with higher cardiac index, longer mechanical ventilation duration and intensive care unit stay, and higher hospital mortality. There was no obvious relation with end-expiratory pressure level nor oxygenation.

\section{Choice of contrast solution}

Studies evaluating TPBT with contrast echocardiography mainly used saline [20] or gelatine [11,21] contrast solution. We chose gelatine solution because it is superior to saline for the opacification of cardiac chambers [22]. However, the size of colloid micro-bubbles is smaller (12 \pm 10 $\mu \mathrm{m})$ than those of saline contrast (24 to $180 \mu \mathrm{m})$ [23]. Because the 'normal' size of pulmonary capillaries is estimated around $8 \mu \mathrm{m}$, some gelatine bubbles could theoretically transit through non-dilated pulmonary capillaries [24]. A suspension of soluble monosaccaride micro-particles with a median bubble size of $3 \mu \mathrm{m}$ was used to detect TPBT in $20 \%$ of stroke patients [25]. This confirms the fact that even bubbles smaller than non-dilated pulmonary capillaries may not cross the pulmonary circulation in all patients. Applying the classification of gelatine-bubble transit proposed by Vedrinne et al. [11] (grade 0, no microbubble in the left atrium; grade 1, a few bubbles in the left atrium; grade 2, moderate bubbles without complete filing of the left atrium; grade 3, many bubbles filing the left atrium completely; and grade 4, extensive bubbles as dense as in the right atrium) to our cohort would result in no grade 3 or 4 TPBT. Other studies have used the threshold of $\geq 3$ saline bubbles transit to detect intrapulmonary shunt in healthy humans during exercise [10]. As we detected TPBT with gelatin contrast solution, our conclusions may not be transposable with the use of saline. Whether the 
Table 1 Clinical and respiratory characteristics of patients with acute respiratory distress syndrome according to transpulmonary bubble transit

\begin{tabular}{|c|c|c|c|}
\hline & \multicolumn{2}{|c|}{ Transpulmonary bubble transit } & \multirow[b]{2}{*}{$p$ value } \\
\hline & Absent-or-minor $(n=159)$ & Moderate-to-large $(n=57)$ & \\
\hline Age, years & $62 \pm 17$ & $61 \pm 18$ & 0.81 \\
\hline Male gender, $n(\%)$ & $110(69 \%)$ & 40 (70\%) & 0.89 \\
\hline McCabe and Jackson class ${ }^{a}$ & & & 0.72 \\
\hline 0 & 99 (62\%) & $34(60 \%)$ & \\
\hline 1 & $39(25 \%)$ & $13(23 \%)$ & \\
\hline 2 & $21(13 \%)$ & $10(18 \%)$ & \\
\hline SAPS II at ICU admission & $55 \pm 23$ & $54 \pm 25$ & 0.66 \\
\hline Cause of lung injury, $n(\%)$ & & & 0.80 \\
\hline Pneumonia & $84(53 \%)$ & $34(60 \%)$ & \\
\hline Aspiration & $40(25 \%)$ & $11(19 \%)$ & \\
\hline Non-pulmonary sepsis & $14(9 \%)$ & $5(9 \%)$ & \\
\hline Other causes & $21(13 \%)$ & $7(12 \%)$ & \\
\hline Berlin category ${ }^{b}$ & & & 0.34 \\
\hline Moderate ARDS & $91(58 \%)$ & $36(64 \%)$ & \\
\hline Severe ARDS & $66(42 \%)$ & $20(36 \%)$ & \\
\hline Cirrhosis & $4(3 \%)$ & $4(7 \%)$ & 0.12 \\
\hline \multicolumn{4}{|l|}{ Respiratory settings ${ }^{b}$} \\
\hline Tidal volume, $\mathrm{mL} / \mathrm{kg}$ & $6.5 \pm 1.0$ & $6.1 \pm 0.8$ & 0.03 \\
\hline Minute ventilation & $10.7 \pm 2.2$ & $10.6 \pm 2.7$ & 0.80 \\
\hline Respiratory rate, bpm & $26 \pm 4$ & $27 \pm 6$ & 0.41 \\
\hline PEEP, $\mathrm{cm} \mathrm{H}_{2} \mathrm{O}$ & $9 \pm 4$ & $9 \pm 3$ & 0.68 \\
\hline Plateau pressure, $\mathrm{cmH}_{2} \mathrm{O}$ & $24 \pm 5$ & $25 \pm 5$ & 0.70 \\
\hline Compliance, $\mathrm{mL} / \mathrm{cmH}_{2} \mathrm{O}$ & $32 \pm 13$ & $29 \pm 11$ & 0.20 \\
\hline Driving pressure, $\mathrm{cmH}_{2} \mathrm{O}$ & $15 \pm 5$ & $15 \pm 5$ & 0.35 \\
\hline \multicolumn{4}{|l|}{ Arterial blood gases ${ }^{c}$} \\
\hline $\mathrm{PaO}_{2} / \mathrm{FiO}_{2}$ ratio, $\mathrm{mmHg}$ & $120 \pm 56$ & $125 \pm 56$ & 0.53 \\
\hline $\mathrm{FiO} 2(\%)$ & $85 \pm 19$ & $80 \pm 21$ & 0.14 \\
\hline $\mathrm{PaO}_{2}, \mathrm{mmHg}$ & $99 \pm 42$ & $96 \pm 40$ & 0.66 \\
\hline Oxygenation Index & $19 \pm 10$ & $19 \pm 13$ & 0.59 \\
\hline $\mathrm{PaCO}_{2}, \mathrm{mmHg}$ & $43 \pm 12$ & $46 \pm 14$ & 0.21 \\
\hline $\mathrm{pH}$ & $7.32 \pm 0.12$ & $7.33 \pm 0.12$ & 0.50 \\
\hline Lactate, mmol/L & $2.3 \pm 2.8$ & $2.2 \pm 2.1$ & 0.87 \\
\hline Septic shock & $105(66 \%)$ & $46(81 \%)$ & 0.04 \\
\hline
\end{tabular}

ARDS, acute respiratory distress syndrome; ${ }^{\mathrm{a}}[44]$; ${ }^{\mathrm{b}}$ respiratory settings and criteria for Berlin definition were recorded at the time of transesophageal echocardiography; $P E E P$, positive end-expiratory pressure; ' clood gases were recorded on the day of transesophageal echocardiography (latest available before echocardiography) and the proportion of patients receiving nitric oxide on that day was similar in the group with moderate-to-large TPBT compared to absent-or-minor group (11 [19\%] vs. 22 [14\%], $p=0.34$ ).

use of both contrast solutions could help distinguish between intrapulmonary shunt due to pulmonary capillary distention versus intrapulmonary arteriovenous shunts needs further studies.

\section{Mechanisms of TPBT}

Detection of transpulmonary transit of small-sized bubbles may result from several mechanisms, including transit through perfused but non-aerated lung areas, transit through dilated capillaries, or opening of dynamic intrapulmonary arteriovenous anastomosis.

Non-aerated lung areas as a result of lung edema are a hallmark of ARDS. In our study, patients with large TPBT tended to have a more severe ARDS, as attested by a trend towards a lower compliance and a higher plateau and driving pressure despite lower tidal volumes. Because of 
Table 2 Hemodynamic and echocardiographic variables in patients with acute respiratory distress syndrome according to transpulmonary bubble transit

\begin{tabular}{|c|c|c|c|c|}
\hline & & Transpulmonary & & \\
\hline & $N^{\mathrm{a}}$ & $\begin{array}{l}\text { Absent-or-minor } \\
(n=159)\end{array}$ & $\begin{array}{l}\text { Moderate-to-large } \\
(n=57)\end{array}$ & $p$ value \\
\hline Hemodynamic variables ${ }^{b}$ & & & & \\
\hline Heart rate, bpm & 212 & $96 \pm 26$ & $105 \pm 24$ & 0.02 \\
\hline Heart rate/respiratory rate ratio & 205 & $3.8 \pm 1.1$ & $4.1 \pm 1.1$ & 0.15 \\
\hline Systolic arterial pressure, $\mathrm{mmHg}$ & 205 & $112 \pm 20$ & $113 \pm 22$ & 0.94 \\
\hline Mean arterial pressure, $\mathrm{mmHg}$ & 202 & $74 \pm 13$ & $75 \pm 14$ & 0.86 \\
\hline Hemodynamic support ${ }^{\mathrm{b}}$ & 216 & & & \\
\hline Norepinephrine & & $101(64 \%)$ & $35(61 \%)$ & 0.78 \\
\hline Dobutamine & & $6(4 \%)$ & $3(5 \%)$ & 0.63 \\
\hline Epinephrine & & $9(6 \%)$ & $4(7 \%)$ & 0.71 \\
\hline Echocardiographic variables & & & & \\
\hline Superior vena cava respiratory collapsibility, \% & 181 & $20(14 \%)$ & $13(26 \%)$ & 0.047 \\
\hline Maximum atrial septal excursion, $\mathrm{mm}$ & 162 & $12 \pm 4$ & $12 \pm 4$ & 0.82 \\
\hline E/A ratio & 171 & $1.2 \pm 0.5$ & $1.0 \pm 0.4$ & 0.02 \\
\hline LV systolic function & 59 & $52 \pm 18$ & $57 \pm 13$ & 0.46 \\
\hline Cardiac index, $\mathrm{L} / \mathrm{min} / \mathrm{m}^{2}$ & 131 & $2.6 \pm 0.9$ & $3.3 \pm 1.2$ & $<0.01$ \\
\hline Systolic pulmonary artery pressure, $\mathrm{mmHg}$ & 146 & $33 \pm 17$ & $35 \pm 20$ & 0.78 \\
\hline Acute cor pulmonale, $n(\%)$ & 216 & $35(22 \%)$ & $11(19 \%)$ & 0.56 \\
\hline
\end{tabular}

${ }^{a} N$, number of patients in which the parameter could be assessed; ${ }^{b}$ hemodynamic variables were recorded at the time of transesophageal echocardiography; $P E E P$, positive end-expiratory pressure; E/A ratio, ratio of early $(E)$ over late $(A)$ peak velocities at the mitral valve; $L V$, left ventricle.

their small size, we cannot exclude that bubbles may have transited through normal-sized capillaries, especially in perfused but non-ventilated areas. Patients with moderate-to large TPBT had a lower tidal volume as compared to others. One hypothesis could be a lesser compression of intra-alveolar capillaries leading to greater TPBT.

The size distribution of pulmonary capillaries during ARDS is not precisely known, but nests of dilated capillaries that abnormally admitted contrast medium into the pulmonary veins were reported in post-mortem arteriogram studies [26]. Sepsis may enhance pulmonary vessels vasodilatation through prostanoids [27] or the nitric oxide pathway [28]. In healthy humans, exercise and hypoxia may induce opening of intrapulmonary arteriovenous anastomosis (IPAV) [29]. IPAV opening is also enhanced by supine position [29], and catecholamine infusion [9]. To date, the precise magnitude of IPAV during ARDS is unknown, and the importance of blood flow through these anastomoses to the efficiency of pulmonary gas exchange remains controversial [30].

In subgroup analysis, cirrhosis was more prevalent in patients with large TPBT. Cirrhotic patients exhibit vasodilatation of pulmonary pre-capillary and capillary vessels (possibly triggered by enhanced pulmonary production of nitric oxide [31]), leading to arteriovenous communications, intrapulmonary shunt, and the hepatopulmonary syndrome. Increased blood flow through these dilated capillaries is further enhanced by the impairment of hypoxic vasoconstriction.

\section{Role of cardiac index}

Septic shock was more frequent in patients with moderateto-large TPBT in our study and probably explains the association with higher values of heart rate, cardiac index, and features of hypovolemia (collapsibility of superior vena cava and lower E/A ratio). These latest features were not associated with lower cardiac index, probably because heart rate was also higher. Tachycardia may increase TPBT via a decrease in pulmonary capillary transit time [32]. Previous reports in experimental models of acute lung injury [33], healthy humans [34], and ARDS patients [35-37] showed an increase in intrapulmonary shunt with increased cardiac output via capillary distension [38] and/or recruitment [39,40], especially in nonventilated lung regions. It is, however, difficult to conclude whether higher cardiac output is a cause or a consequence of intrapulmonary shunt, because severe dilatation or arteriovenous anastomosis could theoretically lead to higher cardiac index via an alleviation of pulmonary vascular resistances. In subgroup analysis, moderate TPBT was associated with hypercapnia. Hypercapnia 
Table 3 Clinical and respiratory characteristics of patients with acute respiratory distress syndrome according to transpulmonary bubble transit (subgroup analysis)

\begin{tabular}{|c|c|c|c|c|}
\hline & \multicolumn{3}{|c|}{ Transpulmonary bubble transit } & \multirow[b]{2}{*}{$p$ value } \\
\hline & $\begin{array}{l}\text { Absent to minor } \\
(n=159)\end{array}$ & $\begin{array}{l}\text { Moderate } \\
(n=42)\end{array}$ & $\begin{array}{l}\text { Large } \\
(n=15)\end{array}$ & \\
\hline Age, years & 63 (53 to 76$)$ & 64 (48 to 74$)$ & $72(53$ to 78$)$ & 0.64 \\
\hline Male gender, $n(\%)$ & $110(69.2 \%)$ & $30(71.4 \%)$ & $10(66.7 \%)$ & 0.93 \\
\hline McCabe and Jackson class* & & & & 0.12 \\
\hline 0 & 99 (62.3\%) & $29(69 \%)$ & $5(33.3 \%)$ & \\
\hline 1 & $39(24.5 \%)$ & $8(19 \%)$ & $5(33.3 \%)$ & \\
\hline 2 & $21(13.2 \%)$ & $5(11.9 \%)$ & $5(33.3 \%)$ & \\
\hline SAPS II at ICU admission & 55 (38 to 69) & 45 (32 to 66$)$ & 69 (47 to 81$)$ & 0.15 \\
\hline Cause of lung injury, $n(\%)$ & & & & 0.67 \\
\hline Pneumonia & $84(52.8 \%)$ & $23(54.8 \%)$ & $11(73.3 \%)$ & \\
\hline Aspiration & $40(25.2 \%)$ & $10(23.8 \%)$ & $1(6.7 \%)$ & \\
\hline Non-pulmonary sepsis & $14(8.8 \%)$ & $3(7.1 \%)$ & $2(13.3 \%)$ & \\
\hline Other causes & $21(13.2 \%)$ & $6(14.3 \%)$ & $1(6.7 \%)$ & 0.59 \\
\hline \multicolumn{5}{|l|}{ Berlin category } \\
\hline Moderate ARDS & $91(58.0 \%)$ & $26(61.9 \%)$ & $10(71.4 \%)$ & \\
\hline Severe ARDS & $66(42.0 \%)$ & $16(38.1 \%)$ & $4(28.6 \%)$ & \\
\hline Cirrhosis & $4(2.5 \%)$ & $1(2.4 \%)$ & $3(20.0 \%)^{a, b}$ & 0.003 \\
\hline \multicolumn{5}{|l|}{ Respiratory settings\# } \\
\hline Tidal volume, mL/kg & $6.3(6.0$ to 7.0$)$ & 6.1 (5.7 to 6.6) & 6.1 (5.9 to 6.6) & 0.06 \\
\hline Minute ventilation & 10.6 (9.0 to 12.0$)$ & 10.5 (8.7 to 12.2$)$ & $10.0(9.1$ to 12.8$)$ & 0.95 \\
\hline Respiratory rate, bpm & 25 (23 to 30$)$ & 28 (24 to 30$)$ & 25 (22 to 30$)$ & 0.46 \\
\hline PEEP, $\mathrm{cmH}_{2} \mathrm{O}$ & $10(5$ to 12$)$ & 10 (7 to 10$)$ & 9 (5 to 12$)$ & 0.86 \\
\hline Plateau pressure, $\mathrm{cmH}_{2} \mathrm{O}$ & 25 (21 to 28$)$ & 24 (20 to 27 ) & 28 (24 to 28$)$ & 0.26 \\
\hline Compliance, $\mathrm{mL} / \mathrm{cmH}_{2} \mathrm{O}$ & 30 (22 to 38$)$ & 28 (21 to 39$)$ & 25 (20 to 30$)$ & 0.27 \\
\hline Driving pressure, $\mathrm{CmH}_{2} \mathrm{O}$ & 15 (11 to 18$)$ & 14 (11 to 19$)$ & 17 (15 to 20$)$ & 0.14 \\
\hline \multicolumn{5}{|l|}{ Arterial blood gases\$ } \\
\hline $\mathrm{PaO}_{2} / \mathrm{FiO}_{2}$ ratio, $\mathrm{mmHg}$ & 112 (81 to 150$)$ & 115 (77 to 161$)$ & 132 (100 to 162$)$ & 0.46 \\
\hline $\mathrm{FiO2}(\%)$ & $100(70$ to 100$)$ & $80(60$ to 100$)$ & 80 (60 to 100$)$ & 0.33 \\
\hline $\mathrm{PaO}_{2}, \mathrm{mmHg}$ & $89(70$ to 116$)$ & 87 (69 to 103) & 92 (75 to 158$)$ & 0.44 \\
\hline $\mathrm{PaCO}_{2}, \mathrm{mmHg}$ & 41 (36 to 48 ) & $44(39 \text { to } 51)^{a}$ & $36(33 \text { to } 46)^{b}$ & 0.02 \\
\hline $\mathrm{pH}$ & 7.33 (7.24 to 7.40$)$ & 7.34 (7.29 to 7.41$)$ & 7.35 (7.28 to 7.40$)$ & 0.79 \\
\hline Lactate, mmol/L & 1.3 (0.9 to 2.7$)$ & 1.4 (0.8 to 2.3$)$ & 1.8 (0.8 to 3.1$)$ & 0.87 \\
\hline
\end{tabular}

ARDS, acute respiratory distress syndrome; ${ }^{* 44}$; \#respiratory settings were recorded at the time of transesophageal echocardiography; $P E E P$, positive end-expiratory pressure; \$blood gases were recorded on the day of transesophageal echocardiography (latest available before echocardiography) and the proportion of patients receiving nitric oxide and prone position on the TEE day was similar in the groups with large, moderate, or absent to minor TPBT (2 [13.3\%] vs. 9 [21.4\%] vs. 22 [13.9\%], $p=0.48$; and $1[6.7 \%]$ vs. 7 [16.7\%] vs. 22 [13.8\%], $p=0.63$, respectively); ${ }^{a} p$ value $<0.05$ (corrected Mann-Whitney test after Kruskal-Wallis test) as compared to absent to minor transpulmonary bubble transit; ${ }^{b} P$ value $<0.05$ (corrected Mann-Whitney test after Kruskal-Wallis test) as compared to moderate transpulmonary bubble transit.

has been previously shown to exert a vasoconstrictive effect on pulmonary circulation, but may also increase cardiac output (through peripheral arterial vasodilation) and intrapulmonary shunt [41].

\section{Clinical implications}

Contrary to our expectations, $\mathrm{PaO}_{2} / \mathrm{FiO}_{2}$ ratio did not differ between groups with or without TPBT. Numerous factors influence oxygenation during ARDS, including intrapulmonary shunt, but also effect of low $\mathrm{PvO}_{2}$ on $\mathrm{PaO}_{2}$ [1], intra-cardiac right-to-left shunt (patients with patent foramen ovale shunting were excluded from the study) [2], and low ventilation-perfusion ratio [3]. Higher cardiac index increases intrapulmonary shunt, but also $\mathrm{PvO}_{2}$, and the net effect on $\mathrm{PaO}_{2}$ may vary from one patient to another. Moreover, $\mathrm{PaO}_{2} / \mathrm{FiO}_{2}$ ratio depends on 
Table 4 Outcome of patients with acute respiratory distress syndrome according to transpulmonary bubble transit

\begin{tabular}{|c|c|c|c|}
\hline & \multicolumn{3}{|c|}{ Transpulmonary bubble transit } \\
\hline & $\begin{array}{l}\text { Absent-or-minor } \\
(n=159)\end{array}$ & $\begin{array}{l}\text { Moderate-to-large } \\
(n=57)\end{array}$ & $p$ value \\
\hline Pneumothorax, $n(\%)$ & $8(5 \%)$ & $2(4 \%)$ & 0.64 \\
\hline \multicolumn{4}{|l|}{ Adjunctive therapy, $n(\%)$} \\
\hline Prone positioning & $50(31 \%)$ & $12(21 \%)$ & 0.14 \\
\hline Nitric oxide & $37(23 \%)$ & $14(25 \%)$ & 0.84 \\
\hline ICU mortality, n (\%) & $73(46 \%)$ & $34(60 \%)$ & 0.08 \\
\hline Hospital mortality, n (\%) & $76(48 \%)$ & $36(63 \%)$ & 0.046 \\
\hline 28-day ventilator-free days, mean $\pm S D$ & $9 \pm 10$ & $4 \pm 8$ & $<0.01$ \\
\hline 28-day ICU-free days, mean \pm SD & $6 \pm 9$ & $3 \pm 6$ & $<0.01$ \\
\hline ICU survivors $(n=109)$ & $(n=86)$ & $(n=23)$ & \\
\hline MV duration, mean days \pm SD & $16 \pm 28$ & $28 \pm 30$ & $<0.01$ \\
\hline ICU duration, mean days \pm SD & $25 \pm 35$ & $35 \pm 33$ & 0.03 \\
\hline
\end{tabular}

$I C U$, intensive care unit; $M V$, mechanical ventilation; $S D$, standard deviation.

$\mathrm{FiO}_{2}$ in a non-linear relationship which is influenced by the severity of shunt [42]. Increased PEEP levels did not alter TPBT magnitude in the vast majority of patients tested (92.5\%), whereas TPBT was lessened or enhanced in rare cases. Higher PEEP levels may decrease shunt via improved lung recruitment and/or decreased cardiac output. However, these two mechanisms may be inversely related during ARDS [15]. In addition, higher PEEP levels could act differently on the size of pulmonary capillaries depending on their location, with collapse of intra-alveolar vessels and dilation of extra-alveolar capillaries [43], leading to opposite effects on intrapulmonary shunt. Last, alteration of oxygenation may require more severe intrapulmonary shunts than those observed in the present study.

TPBT was associated with longer duration of mechanical ventilation and ICU stay. No significant difference in ICU mortality was found, but hospital mortality was higher in the group of patients with moderate-to-large TPBT. The latter finding could be explained by a poorer condition after longer mechanical ventilation and ICU stay. Septic shock, which was more frequent in patients with moderate-to-large TPBT in our study, could also explain these findings.

\section{Study limitations}

Limitations of this study include its mono-centric design and the seven-year period inclusion. However, our mechanical ventilation strategy did not vary during the study period. Second, we only report on a single TEE within three days of ARDS start. Third, we did not measure cardiac output and lung recruitment during PEEP changes. Fourth, we did not compare contrast TEE with other methods of measurement of shunt, such as measurement of venous admixture using a pulmonary arterial catheter, and as previously stated, detection of TPBT cannot be used as a direct surrogate of intrapulmonary shunt. Fifth, we did not explore TPBT in other ICU patients without ARDS and could not report on its general prevalence in critically ill patients and during mechanical ventilation or sepsis. In physiological studies performed in healthy humans, TPBT could be detected during exercise but not at rest $[9,10]$.

\section{Conclusions}

In conclusion, we report the first evaluation of contrast echocardiography to detect TPBT in the setting of ARDS. Although moderate-to-large TPBT was identified in $26 \%$ of patients, we did not detect any massive TPBT in this setting. TPBT did not influence oxygenation, and may not be used as a direct surrogate of intrapulmonary shunt during ARDS. TPBT was mainly associated with a hyperdynamic hemodynamic status and septic shock. Whether TPBT is present in ventilated patients with septic shock but not ARDS requires further studies.

\section{Abbreviations}

ARDS: acute respiratory distress syndrome; ICU: intensive care unit; IPAV: intrapulmonary arteriovenous anastomosis; LV: left ventricle; MV: mechanical ventilation; PASP: pulmonary artery systolic pressure; PEEP: positive end-expiratory pressure; PFO: patent foramen ovale; Pplat: plateau pressure; RV: right ventricle; SVC: superior vena cava; TEE: transesophageal echocardiography; TPBT: transpulmonary bubble transit; Vt: tidal volume.

\section{Competing interests}

The authors declare that they have no competing interests.

\section{Authors' contributions}

AMD designed the study. FB, AMD, KR, AWT, FRC, RL, and EV performed TEE and collected data. FB and AMD evaluated echocardiographic images off-line, analysed the data, and wrote the article. LB and CBB supervised the study and revised the manuscript. All authors read and approved the final manuscript. 


\section{Acknowledgments}

The authors wish to thank Prof. Christophe Delclaux, M.D, Ph.D, for his reviewing of the manuscript and his advice.

\section{Funding}

This study was funded by the non-profit public organization Assistance Publique-Hôpitaux de Paris (AP-HP).

\section{Author details}

${ }^{1}$ AP-HP, Hôpital Henri Mondor, DHU A-TVB, Service de Réanimation Médicale, Groupe de recherche CARMAS, 51 Av Mal de Lattre de Tassigny, Créteil 94010, France. ${ }^{2}$ INSERM, Unité U955 (IMRB), 8 rue du Général Sarrail, Créteil 94010, France. ${ }^{3}$ Faculté de Médecine, Université Paris Est Créteil, 8, rue du Général Sarrail, Créteil 94010, France. ${ }^{4} \mathrm{CHU}$ de Poitiers, Réanimation médicale, Poitiers, France; INSERM CIC 1402 (équipe 5 ALIVE), Université de Poitiers, 2 Rue de la Milétrie, 86021 Poitiers, France. ${ }^{5}$ Servei de Medicina Intensiva, Hospital Verge de la Cinta, Carrer de les Esplanetes, 14, 43500 Tortosa, Tarragona, Spain. ${ }^{6}$ Centre Hospitalier Intercommunal de Créteil, Réanimation polyvalente, 40 avenue de Verdun, 94010 Créteil, France. ${ }^{7}$ Centre Hospitalier Saint Luc Saint Joseph, Réanimation Polyvalente, 20, quai Claude Bernard, 69007 Lyon, France. ${ }^{8}$ Saint Michael's Hospital, 30 Bond Street, ON M5B 1 W8 Toronto, Canada.

Received: 13 January 2015 Accepted: 9 March 2015

Published online: 24 March 2015

\section{References}

1. Kelman GR, Nunn JF, Prys-Roberts C, Greenbaum R. The influence of cardiac output on arterial oxygenation: a theoretical study. $\mathrm{Br} J$ Anaesth. 1967;39(6):450-8.

2. Mekontso Dessap A, Boissier F, Leon R, Carreira S, Campo FR, Lemaire F, et al. Prevalence and prognosis of shunting across patent foramen ovale during acute respiratory distress syndrome. Crit Care Med. 2010;38(9):1786-92

3. Dantzker DR, Brook CJ, Dehart P, Lynch JP, Weg JG. Ventilation-perfusion distributions in the adult respiratory distress syndrome. Am Rev Respir Dis. 1979;120(5):1039-52.

4. Matamis D, Lemaire F, Harf A, Teisseire B, Brun-Buisson C. Redistribution of pulmonary blood flow induced by positive end-expiratory pressure and dopamine infusion in acute respiratory failure. Am Rev Respir Dis. 1984;129 (1):39-44.

5. Ralph DD, Robertson HT, Weaver L, Hlastala MP, Carrico CJ, Hudson LD. Distribution of ventilation and perfusion during positive end-expiratory pressure in the adult respiratory distress syndrome. Am Rev Respir Dis. 1985;131(1):54-60.

6. Riley RL, Cournand A. Ideal alveolar air and the analysis of ventilation-perfusion relationships in the lungs. J Appl Physiol. 1949;1(12):825-47.

7. Wagner PD, Saltzman HA, West JB. Measurement of continuous distributions of ventilation-perfusion ratios: theory. J Appl Physiol. 1974;36(5):588-99.

8. Cressoni M, Caironi P, Polli F, Carlesso E, Chiumello D, Cadringher P, et al. Anatomical and functional intrapulmonary shunt in acute respiratory distress syndrome. Crit Care Med. 2008;36(3):669-75.

9. Laurie SS, Yang X, Elliott JE, Beasley KM, Lovering AT. Hypoxia-induced intrapulmonary arteriovenous shunting at rest in healthy humans. J Appl Physiol (1985). 2010;109(4):1072-9.

10. Lovering AT, Romer LM, Haverkamp HC, Pegelow DF, Hokanson JS, Eldridge MW. Intrapulmonary shunting and pulmonary gas exchange during normoxic and hypoxic exercise in healthy humans. J Appl Physiol (1985). 2008;104(5):1418-25.

11. Vedrinne JM, Duperret S, Bizollon T, Magnin C, Motin J, Trepo C, et al. Comparison of transesophageal and transthoracic contrast echocardiography for detection of an intrapulmonary shunt in liver disease. Chest. 1997;111(5):1236-40.

12. Boissier F, Katsahian S, Razazi K, Thille AW, Roche-Campo F, Leon R, et al. Prevalence and prognosis of cor pulmonale during protective ventilation for acute respiratory distress syndrome. Intensive Care Med. 2013;39(10):1725-33.

13. Ranieri VM, Rubenfeld GD, Thompson BT, Ferguson ND, Caldwell E, Fan E, et al. Acute respiratory distress syndrome: the Berlin definition. JAMA. 2012;307(23):2526-33.

14. Mercat A, Richard JC, Vielle B, Jaber S, Osman D, Diehl JL, et al. Positive end-expiratory pressure setting in adults with acute lung injury and acute respiratory distress syndrome: a randomized controlled trial. JAMA. 2008;299(6):646-55.

15. Mekontso Dessap A, Charron C, Devaquet J, Aboab J, Jardin F, Brochard L, et al. Impact of acute hypercapnia and augmented positive end-expiratory pressure on right ventricle function in severe acute respiratory distress syndrome. Intensive Care Med. 2009;35(11):1850-8.

16. Trachsel D, McCrindle BW, Nakagawa S, Bohn D. Oxygenation index predicts outcome in children with acute hypoxemic respiratory failure. Am J Respir Crit Care Med. 2005;172(2):206-11.

17. Mayo PH, Beaulieu Y, Doelken P, Feller-Kopman D, Harrod C, Kaplan A, et al. American college of chest physicians/La Societe de reanimation de langue Francaise statement on competence in critical care ultrasonography. Chest. 2009;135(4):1050-60.

18. Vieillard-Baron A, Charron C, Chergui K, Peyrouset O, Jardin F. Bedside echocardiographic evaluation of hemodynamics in sepsis: is a qualitative evaluation sufficient? Intensive Care Med. 2006:32(10):1547-52.

19. Jardin F, Dubourg O, Bourdarias JP. Echocardiographic pattern of acute cor pulmonale. Chest. 1997;111(1):209-17.

20. Fischer $\mathrm{CH}$, Campos O, Fernandes WB, Kondo M, Souza FL, De Andrade JL, et al. Role of contrast-enhanced transesophageal echocardiography for detection of and scoring intrapulmonary vascular dilatation. Echocardiography. 2010;27(10):1233-7.

21. Siostrzonek P, Zangeneh M, Gossinger H, Lang W, Rosenmayr G, Heinz G, et al. Comparison of transesophageal and transthoracic contrast echocardiography for detection of a patent foramen ovale. Am J Cardiol. 1991;68(11):1247-9.

22. Tan HC, Fung KC, Kritharides L. Agitated colloid is superior to saline and equivalent to levovist in enhancing tricuspid regurgitation Doppler envelope and in the opacification of right heart chambers: a quantitative, qualitative, and cost-effectiveness study. J Am Soc Echocardiogr. 2002;15 (4):309-15.

23. Nemec JJ, Marwick TH, Lorig RJ, Davison MB, Chimowitz MI, Litowitz H, et al. Comparison of transcranial Doppler ultrasound and transesophageal contrast echocardiography in the detection of interatrial right-to-left shunts. Am J Cardiol. 1991;68(15):1498-502.

24. Butler BD, Hills BA. The lung as a filter for microbubbles. J Appl Physiol Respir Environ Exerc Physiol. 1979;47(3):537-43.

25. Horner S, Ni XS, Weihs W, Harb S, Augustin M, Duft M, et al. Simultaneous bilateral contrast transcranial doppler monitoring in patients with intracardiac and intrapulmonary shunts. J Neurol Sci. 1997;150(1):49-57.

26. Tomashefski Jr JF, Davies P, Boggis C, Greene R, Zapol WM, Reid LM. The pulmonary vascular lesions of the adult respiratory distress syndrome. Am J Pathol. 1983;112(1):112-26.

27. Myers TP, Myers PR, Adams HR, Parker JL. Enhanced prostanoid-mediated vasorelaxation in pulmonary arteries isolated during experimental endotoxemia. Shock. 1999;11(6):436-42.

28. Spohr F, Cornelissen AJ, Busch C, Gebhard MM, Motsch J, Martin EO, et al. Role of endogenous nitric oxide in endotoxin-induced alteration of hypoxic pulmonary vasoconstriction in mice. Am J Physiol Heart Circ Physiol. 2005;289(2):H823-31.

29. Stickland MK, Welsh RC, Haykowsky MJ, Petersen SR, Anderson WD, Taylor DA, et al. Intra-pulmonary shunt and pulmonary gas exchange during exercise in humans. J Physiol. 2004;561(Pt 1):321-9.

30. Lovering AT, Riemer RK, Thebaud B. Intrapulmonary arteriovenous anastomoses: physiol, pathophysiol both? Ann Am Thorac Soc. 2013;10(5):504-8.

31. Rodriguez-Roisin R, Krowka MJ. Hepatopulmonary syndrome-a liver-induced lung vascular disorder. N Engl J Med. 2008;358(22):2378-87.

32. Lindstedt SL. Pulmonary transit time and diffusing capacity in mammals. Am J Physiol. 1984;246(3 Pt 2):R384-8.

33. Freden F, Cigarini I, Mannting F, Hagberg A, Lemaire F, Hedenstierna G. Dependence of shunt on cardiac output in unilobar oleic acid edema: distribution of ventilation and perfusion. Intensive Care Med. 1993;19(4):185-90.

34. Bryan TL, van Diepen S, Bhutani M, Shanks M, Welsh RC, Stickland MK. The effects of dobutamine and dopamine on intrapulmonary shunt and gas exchange in healthy humans. J Appl Physiol (1985). 2012;113(4):541-8.

35. Lemaire F, Gastine H, Regnier B, Teisseire B, Rapin M. Perfusion changes modify intrapulmonary shunting in patients with adult respiratory distress syndrome. Am Rev Respir Dis. 1978;Suppl:117-44.

36. Lynch JP, Mhyre JG, Dantzker DR. Influence of cardiac output on intrapulmonary shunt. J Appl Physiol Respir Environ Exerc Physiol. 1979;46(2):315-21. 
37. Payen DM, Carli PA, Brun-Buisson CJ, Huet YJ, Teisseire BP, Chiron-Payen B, et al. Lower body positive pressure vs. dopamine during PEEP in humans. J Appl Physiol (1985). 1985;58(1):77-82.

38. Glazier JB, Hughes JM, Maloney JE, West JB. Measurements of capillary dimensions and blood volume in rapidly frozen lungs. J Appl Physiol. 1969;26(1):65-76.

39. Fougeres E, Teboul JL, Richard C, Osman D, Chemla D, Monnet X. Hemodynamic impact of a positive end-expiratory pressure setting in acute respiratory distress syndrome: importance of the volume status. Crit Care Med. 2010;38(3):802-7.

40. Warrell DA, Evans JW, Clarke RO, Kingaby GP, West JB. Pattern of filling in the pulmonary capillary bed. J Appl Physiol. 1972;32(3):346-56.

41. Pfeiffer B, Hachenberg T, Wendt M, Marshall B. Mechanical ventilation with permissive hypercapnia increases intrapulmonary shunt in septic and nonseptic patients with acute respiratory distress syndrome. Crit Care Med. 2002;30(2):285-9.

42. Aboab J, Jonson B, Kouatchet A, Taille S, Niklason L, Brochard L. Effect of inspired oxygen fraction on alveolar derecruitment in acute respiratory distress syndrome. Intensive Care Med. 2006;32(12):1979-86.

43. Permutt S WR, Brower RG. How changes in pleural and alveolar pressure cause changes in afterload and preload. In: Marcel Dekker, editor. Heart-lung interaction in Health and Disease. New York; 1989. p. 243-50.

44. McCabe WR. Jackson, GC Gram negative bacteriemia: etiology and ecology. Arch Intern Med. 1962;110(6):847-55.

\section{Submit your manuscript to a SpringerOpen ${ }^{\circ}$ journal and benefit from:}

- Convenient online submission

- Rigorous peer review

- Immediate publication on acceptance

- Open access: articles freely available online

- High visibility within the field

- Retaining the copyright to your article 